\title{
Complete TEM Investigation of a Nitrided Layer for a Cr Alloy Steel
}

\author{
Jean-Noël Locquet $\left({ }^{1}\right)$, Richard Soto $\left({ }^{2}\right)$, Laurent Barrallier $\left({ }^{1}\right)$ \\ and Ahmed Charaï $\left({ }^{2}\right)$ \\ $\left({ }^{1}\right)$ Laboratoire MécaSurf, 2 Cours des Arts et Métiers, 13617 Aix-en-Provence Cedex 1, France \\ $\left({ }^{2}\right) \operatorname{EDIFIS}\left({ }^{*}\right)$, Laboratoire de Métallurgie, Faculté de Saint Jérôme, \\ 13397 Marseille Cedex 20, France
}

(Received June 11, 1997; Accepted January 5, 1998)

\begin{abstract}
PACS.81.65.Lp - Surface hardening: nitridation, carburization,carbonitridation PACS.81.40.-z - Treatment of materials and its effects on microstructure and properties PACS.61.82.Bg - Metals and alloys
\end{abstract}

\begin{abstract}
Un-nitrided material is investigated by TEM in order to identify the different types of precipitates and to determine their respective volume fraction. $\mathrm{M}_{23} \mathrm{C}_{6}$ and $\mathrm{M}_{4} \mathrm{C}_{3}$ carbides are reported. Experimental results are confirmed by thermodynamical calculations. The same material is nitrided in industrial conditions and also investigated by TEM. Crystallographic structures and chemical compositions are determined by Selected Area Electron Diffraction (SAED), Energy Dispersive Spectroscopy (EDS) and Electron Energy Loss Spectroscopy (EELS). V-rich carbonitrides, incoherent globular CrN nitrides and semi-coherent CrN nitrides are reported. In both cases, CrN precipitates have the Baker-Nutting orientation relationship with respect to the ferritic matrix. Their size distributions as a function of depth are studied.
\end{abstract}

\section{Introduction}

Nowadays, nitriding have more and more industrial applications in gears and bearings fields for instance in aeronautics. High hardness, compressive residual stresses and surface fatigue performance increase are the best elements for nitrided parts utilization in industrial systems instead of others technologies. In order to understand the behaviour of nitrided parts during service, the microstructure of nitrided layers must be known as well as possible. These microstructures have already been studied by many authors but in most cases, binary alloys $[1,2]$ or synthetical alloys [3] were studied. Few of them studied industrial alloys. The purpose of this paper is to study by Transmission Electron Microscopy (TEM) the intragranular microstructure of the nitrided layer as well as the initial un-nitrided material for an industrial steel. The chemical composition, the crystallographic structure, the size distributions and the volume fraction of the different types of precipitates are determined as a function of depth.

$\left(^{*}\right)$ UMR 6518 
Table I. - Chemical composition of 32Cr13MoV steel.

\begin{tabular}{|c|c|c|c|c|c|c|c|c|}
\hline & $\mathrm{C}$ & $\mathrm{Si}$ & $\mathrm{Mn}$ & $\mathrm{Cr}$ & $\mathrm{Ni}$ & $\mathrm{Mo}$ & $\mathrm{V}$ & $\mathrm{Fe}$ \\
\hline Chemical composition (wt\%) & 0.305 & 0.33 & 0.47 & 2.92 & 0.14 & 0.87 & 0.30 & Bal. \\
\hline
\end{tabular}

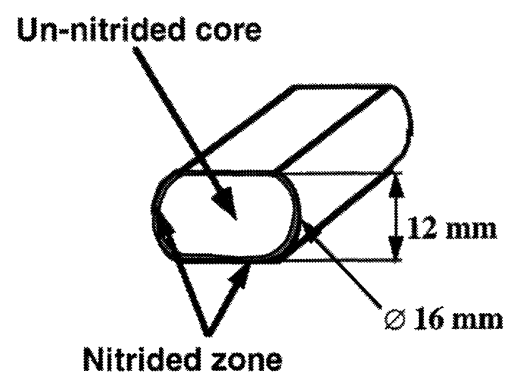

Fig. 1. - Geometry of samples.

\section{Experimental Procedure}

Experiments are made with an industrial French standard $32 \mathrm{Cr} 13 \mathrm{MoV}$ steel. The composition is given in Table I.

Specimens (see Fig. 1) have been oil quenched from $1223 \mathrm{~K}$ and tempered over $873 \mathrm{~K}$ for few hours. Nitriding has been performed in a gas mixture $\mathrm{NH}_{3} / \mathrm{H}_{2}$ at $823 \mathrm{~K}$ for $120 \mathrm{~h}$. TEM observations have been performed on thin foils as well as on extractive carbon film replicas depending which kind of data is needed. Thin foils provide reliable data on volume arrangement of precipitates in the bulk but replicas provide accurate results for EDS experiments and diffraction patterns acquisition since the matrix effect does not influence anymore the measurement. For depth selection of the thin foil in the nitrided layer, the surface was taken as a reference. From a cut slice of material containing the selected depth, mechanical polishing was performed on both sides of the slice in order to reach a thickness of 50-70 $\mu$ m with the aimed depth situated approximately in the center of the slice. The right position of the selected depth was controlled during mechanical polishing by measurements of the slice thickness with an accuracy of $1 \mu \mathrm{m}$.

TEM observations have been made using a JEOL JEM 2010F URP22 microscope equipped with an EDS-Kevex device and with an ELS-Gatan Imaging Filter. Images are recorded on photographic films.

Thermodynamical calculations were performed with THERMOCALC software [4]. From the nominal composition of the steel and the tempering (or nitriding) temperature, phases appearing at the chemical equilibrium are determined and their respective volume fraction are calculated [5]. Calculations are based on the Gibb's free energy minimization of the system defined by iron and solute atoms (Cr, Mo, V, C, N). For each type of precipitates, alloying elements atomic fractions are also available.

Quantitative Wavelength Dispersive Spectroscopy (WDS) measurements of carbon and nitrogen as a function of depth have been made with a CAMECA device on nitrided layers. 


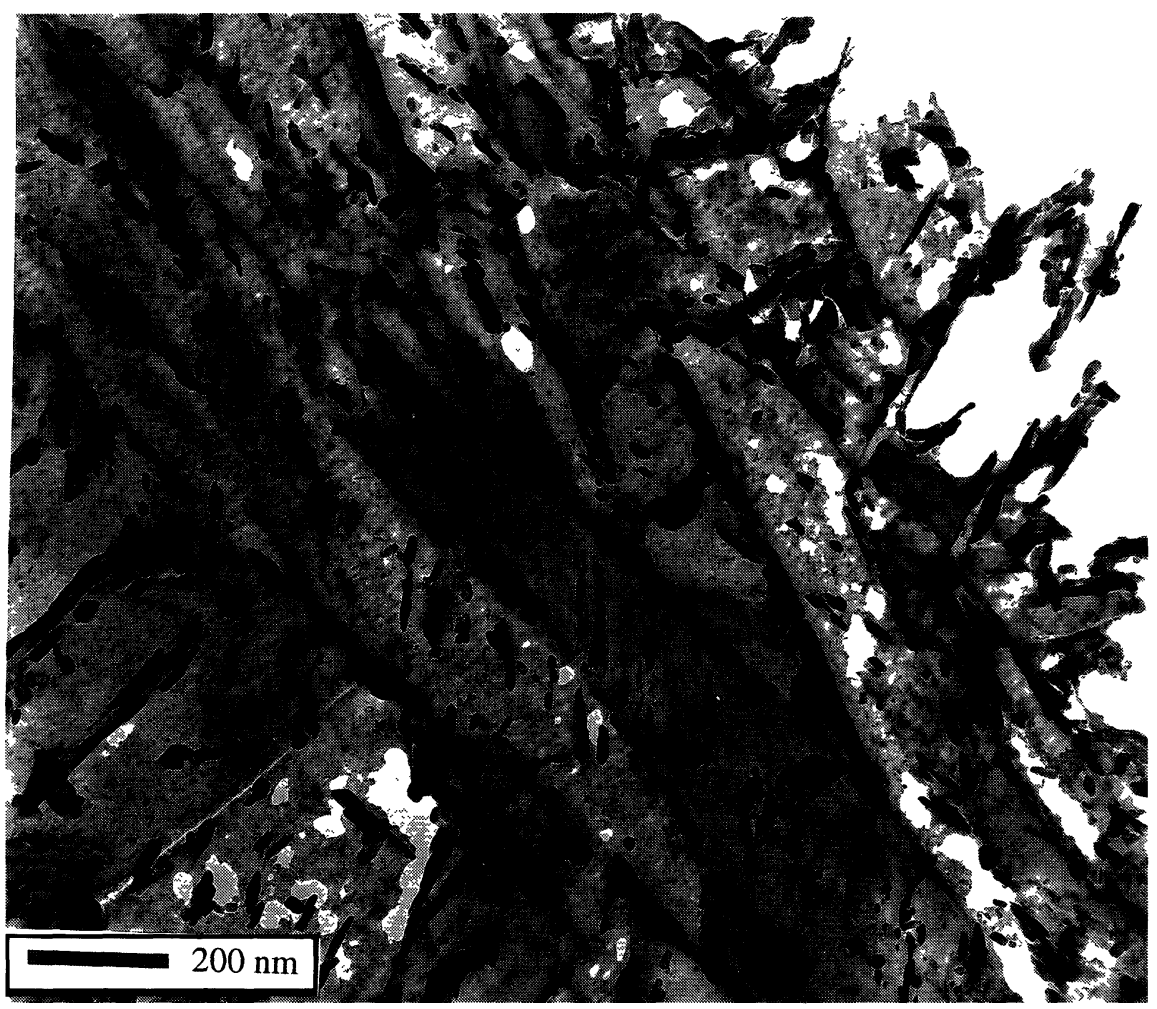

Fig. 2. - TEM micrograph from a thin foil of the un-nitrided core for quenched-tempered $32 \mathrm{Cr} 13 \mathrm{MoV}$ steel.

Chemical standards necessary for the analysis were synthetic iron nitride $\gamma^{\prime}-\mathrm{Fe}_{4} \mathrm{~N}$ for nitrogen and diamond for carbon.

\section{Un-nitrided Material}

\subsection{Microstructure Analysis and Identification of Precipitates}

The quenched-tempered material exhibits a tempered martensite microstructure constituted by laths $200 \mathrm{~nm}$ wide and $1 \mu \mathrm{m}$ long (see Fig. 2). In this figure, intralath and interlath precipitates generated by the tempering treatment appear as small black particles. The width of intralath precipitates is situated between 10 and $20 \mathrm{~nm}$. Their lenght is situated between 50 and $200 \mathrm{~nm}$. For interlath precipitates, dimensions are quite the same in width, but some of them can reach $400 \mathrm{~nm}$ in length due to the enhanced diffusion through interlath boundaries. Chemical and crystallographic data have been obtained from extracted precipitates on carbon film replicas. The SAED provides their crystallographic structure. For both interlath and intralath precipitates, $\mathrm{M}_{23} \mathrm{C}_{6}$ carbide has been identified with a Face Centered Cubic (FCC) structure and a lattice parameter $a_{\mathrm{M}_{23} \mathrm{C}_{6}}=1.06 \mathrm{~nm}$ (see Fig. 3). Some characteristics of these precipitates taken from literature [6] are summarized in Table II. Semi quantitative calculations on EDS spectra obtained from several precipitates provide their mean chemical composition (see Tab. III). These carbides are derived from $\mathrm{Cr}_{23} \mathrm{C}_{6}$ structure by progressive 


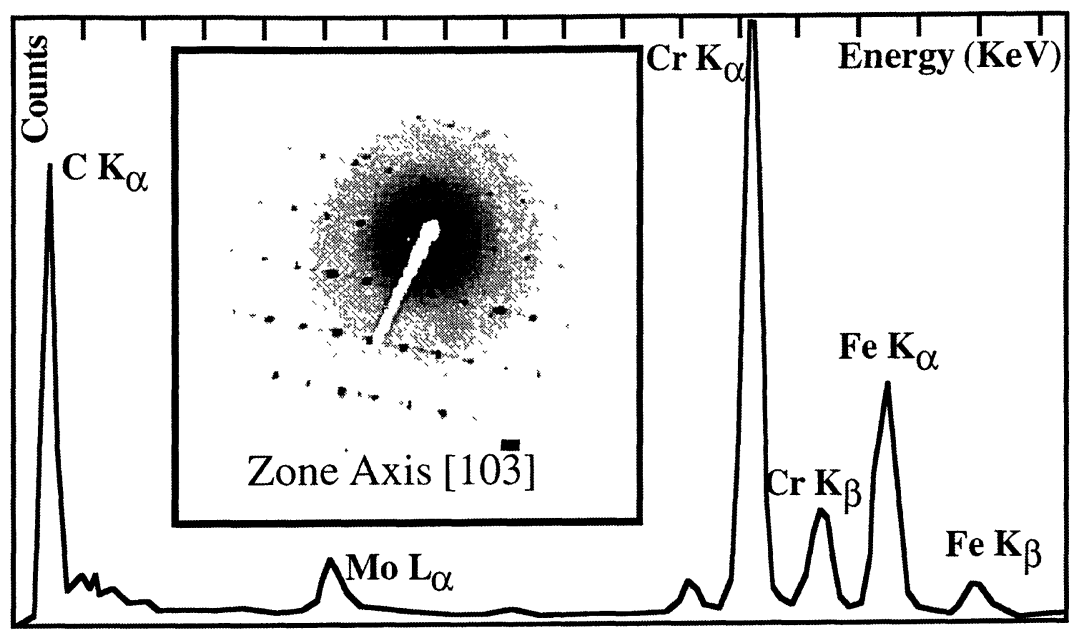

Fig. 3. - EDS spectrum and SAED pattern for $\mathrm{M}_{23} \mathrm{C}_{6}$ precipitates.

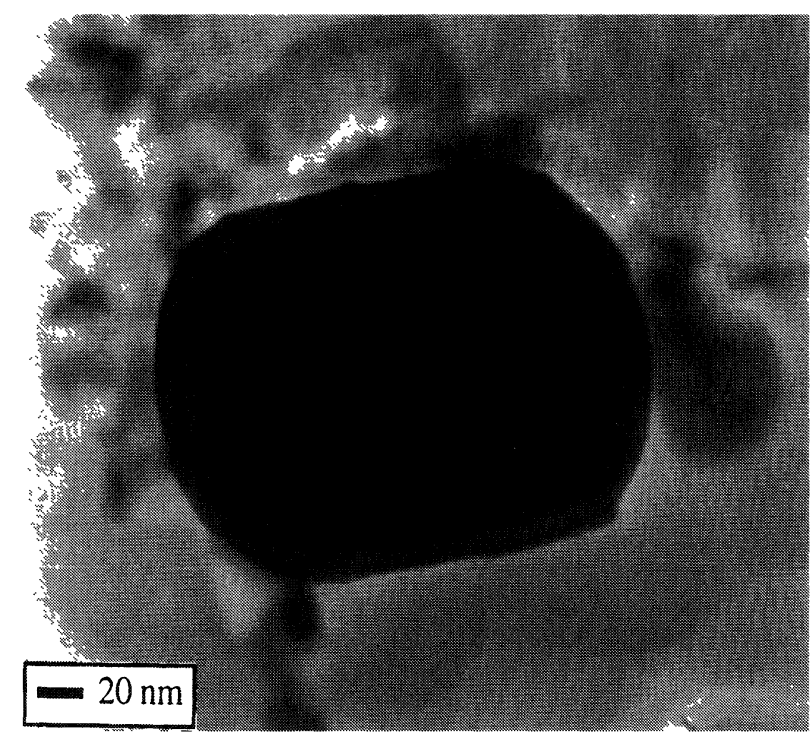

Fig. 4. - TEM micrograph from a carbon film replica of $\mathrm{M}_{4} \mathrm{C}_{3}$ type precipitate.

substitution of chromium atoms by iron and molybdenum atoms. Indeed, $\mathrm{Cr}_{23} \mathrm{C}_{6}$ structure can dissolve up to 30 at\% of Fe and larger atoms such as Mo atoms are necessary to fill in some atomic positions in the lattice in order to stabilize the structure and enable it to dissolve more Fe atoms. From [6], the whole theoretical amount of Mo which can enter in this structure is established around 9 at\%. This is the most stable configuration. In this study, $\mathrm{M}_{23} \mathrm{C}_{6}$ carbides have reached this configuration since EDS spectra analysis gives exactly this value.

The un-nitrided material also contains an other type of precipitates (see Fig. 4). Thin foils observations reveal a globular shape and a random distribution. Their diameters are ranging between 100 to $250 \mathrm{~nm}$. Their FCC structure is elucidated from SAED patterns and their 


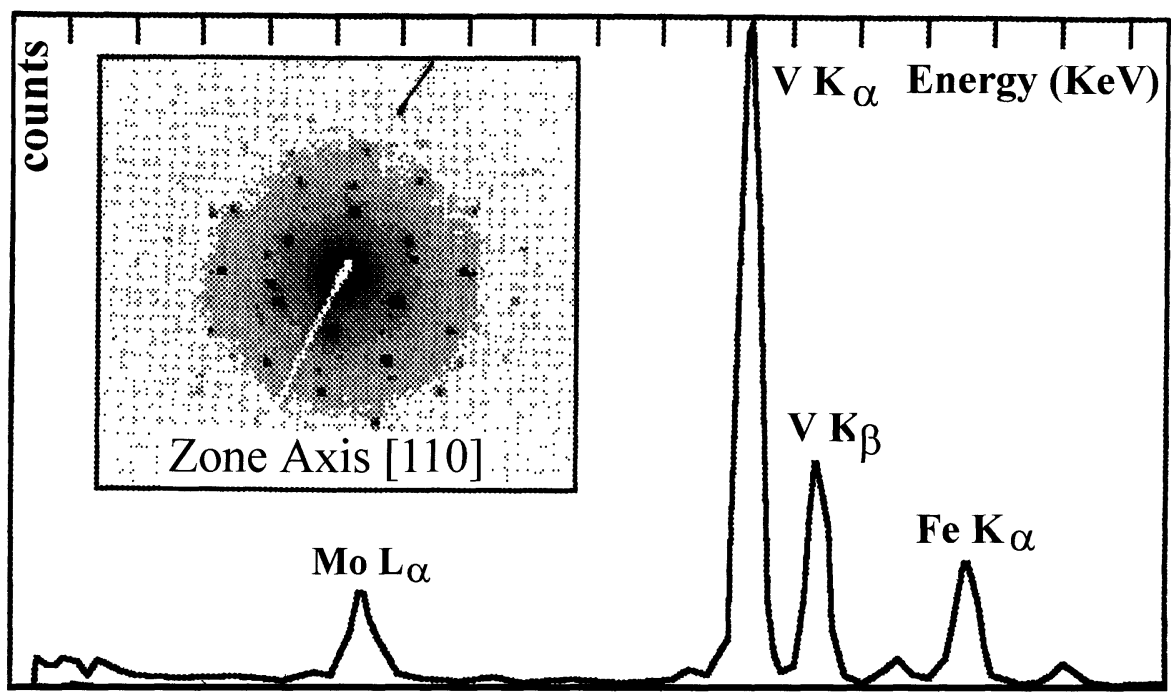

Fig. 5. - EDS spectrum and SAED pattern for $\mathrm{M}_{4} \mathrm{C}_{3}$ precipitates.

V-rich composition is provided by EDS spectra (see Fig. 5). These carbides are $\mathrm{M}_{4} \mathrm{C}_{3}$ type. Their experimental mean chemical composition is presented in Table III and compared with values obtained by the thermodynamical calculations. Both figures are not in a very good agreement. This discrepancy can be explained as follows: thin foils TEM observations on the as-quenched material have shown the presence of these carbides. Moreover, a thermodynamical calculation using THERMOCALC software provides a dissolution temperature for this type of carbides at $1223 \mathrm{~K}$. This temperature is exactly the austenitization temperature but these calculations do not take into account the reaction kinetics. As carbide dissolution is a time dependant phenomenon, the austenitization treatment can not be long enough to dissolve them completely. As a result, during tempering treatment, they can act as heterogenous nuclei for $\mathrm{M}_{4} \mathrm{C}_{3}$ precipitation. Thus, this way of precipitation do not lead to the equilibrium composition.

\subsection{Volume Fractions Evaluation}

As this material is going to be nitrided, volume fraction of precipitates must be known in order to get reliable data of the initial state before nitriding. This evaluation has been performed by three different means.

- With direct observations on thin foils. Precipitate sizes are determined from TEM micrographs and the total investigated surface is calculated from the magnification value. Thus, the surface density of precipitates can be obtained. In order to determine the volume fraction, thin foil thickness is needed. This data is obtained by geometrical considerations. The variation of the distance - in respect with the tilt angle - between two points situated on each face of the foil, allows the determination of the foil thickness between these two points. A good precision is reached with few attempts. Assuming an ellipsoid shape for these precipitates, the volume fraction can be calculated.

- By an indirect way with chemical considerations. Quantitative WDS experiments provide the real composition of the steel. Volume fraction of precipitates can be calculated from 
Table II. - Ferrite and precipitates characteristics from Goldschmidt [6].

\begin{tabular}{|c|c|c|c|c|}
\hline & $\begin{array}{c}\text { Crystal } \\
\text { Structure }\end{array}$ & $\begin{array}{c}\text { Lattice } \\
\text { Parameter }(\mathrm{nm})\end{array}$ & $\begin{array}{c}\text { Heat of } \\
\text { Formation }(\mathrm{kJ} / \mathrm{mol})\end{array}$ & $\begin{array}{c}\text { Mass } \\
\text { Volume }\left(\mathrm{cm}^{3} / \mathrm{g}\right)\end{array}$ \\
\hline Ferrite & BCC & 0.28664 & - & 0.127 \\
\hline $\mathrm{CrN}$ & FCC & 0.4140 & -118 & 0.164 \\
\hline$(\mathrm{Cr}, \mathrm{Fe}, \mathrm{Mo})_{23} \mathrm{C}_{6}$ & FCC & 1.060 & -68.5 & 0.143 \\
\hline$(\mathrm{V}, \mathrm{Cr}, \mathrm{Fe}, \mathrm{Mo})_{4} \mathrm{C}_{3}$ & FCC & 0.41655 at $\mathrm{VC}_{0.87}$ & -102 & 0.177 at $\mathrm{VC}$ \\
& & 0.41310 at $\mathrm{VC}_{0.73}$ & & 0.178 at $\mathrm{VC}_{0.78}$ \\
\hline $\mathrm{VN}$ & FCC & 0.4169 & -251 & 0.164 \\
\hline
\end{tabular}

Table III. - Experimental and calculated alloying elements fractions for un-nitrided material precipitates.

\begin{tabular}{|c|c|c|}
\hline Chemical compositions & Experimental & Calculated \\
\hline & $60 \pm 3$ at\% $\mathrm{Cr}$ & $53 \mathrm{at} \% \mathrm{Cr}$ \\
$\mathrm{M}_{23} \mathrm{C}_{6}$ & $31 \pm 2 \mathrm{at} \% \mathrm{Fe}$ & $37 \mathrm{at} \% \mathrm{Fe}$ \\
& $9 \pm 1 \mathrm{at} \% \mathrm{Mo}$ & $10 \mathrm{at} \% \mathrm{Mo}$ \\
\hline & $65 \pm 3 \mathrm{at} \% \mathrm{~V}$ & $88 \mathrm{at} \% \mathrm{~V}$ \\
$\mathrm{M}_{4} \mathrm{C}_{3}$ & $11 \pm 1 \mathrm{at} \% \mathrm{Fe}$ & - \\
& $14 \pm 1 \mathrm{at} \% \mathrm{Cr}$ & $2 \mathrm{at} \% \mathrm{Cr}$ \\
& $10 \pm 1 \mathrm{at} \% \mathrm{Mo}$ & $10 \mathrm{at} \% \mathrm{Mo}$ \\
\hline
\end{tabular}

the carbon content assuming all carbon atoms have precipitated and the solid solution of carbon in ferrite is negligible.

- By a theoretical way with thermodynamical calculations using THERMOCALC software.

Results are summarized in Table IV.

The three methods provide results in good agreement for both types of precipitates. For industrial applications, all three methods have to be performed at the same time. Thermodynamical calculations can be carried out as a first step to determine which kind of precipitates can occur in the defined metallurgical system. TEM observations are then necessary to experimentally confirm and complete the data obtained from calculations.

Table IV. - Experimental and calculated volume fraction for un-nitrided core precipitates.

\begin{tabular}{|c|c|c|c|}
\hline & \multicolumn{3}{|c|}{ Volume fractions (\%) } \\
\hline & Thermocalc & TEM observations & Calculated \\
\hline $\mathrm{M}_{23} \mathrm{C}_{6}$ & 6.00 & $6.8 \pm 1$ & $5.3 \pm 0.3$ \\
\hline $\mathrm{M}_{4} \mathrm{C}_{3}$ & 0.45 & $0.70 \pm 0.5$ & $0.69 \pm 0.1$ \\
\hline
\end{tabular}




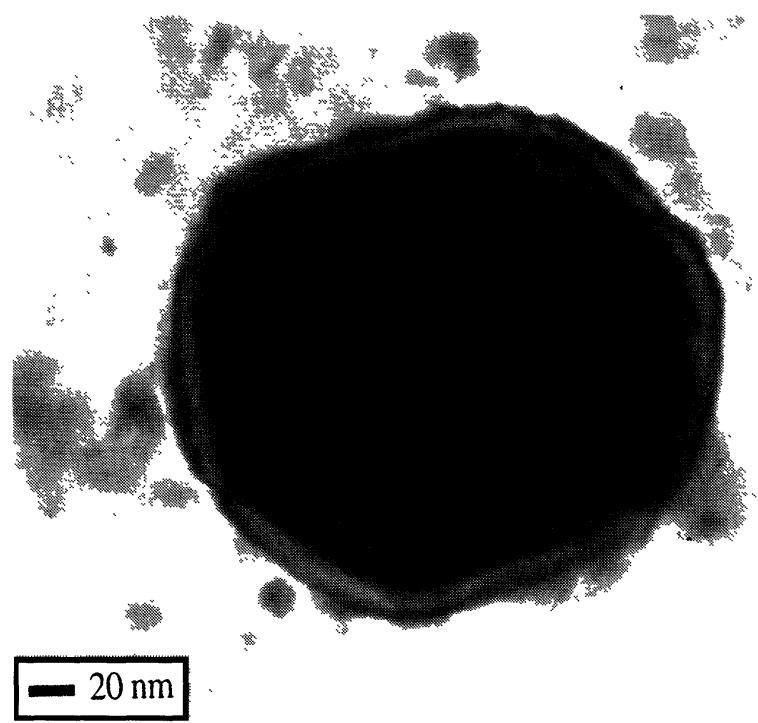

Fig. 6. - TEM micrograph from carbon film replica of VN type precipitates.

\subsection{Addition Elements Balance}

The characterization of the un-nitrided material has been achieved by th precipitates identification and the evaluation of their volume fraction. This material is nitrided and it is interesting to know if some addition elements are still as a solid solution in the ferritic matrix in order to form nitrides during nitriding treatment. From the chemical composition of $\mathrm{M}_{23} \mathrm{C}_{6}$ and $\mathrm{M}_{4} \mathrm{C}_{3}$ carbides (see Tab. III) and their respective volume fractions (see Tab. IV), the macroscopic chromium content precipitated in $\mathrm{M}_{23} \mathrm{C}_{6}$ and $\mathrm{M}_{4} \mathrm{C}_{3}$ carbides can be calculated. It is found equal to $2.5 \pm 0.1 \mathrm{wt} \%$. A comparison with the nominal chromium content of the studied steel $(2.9 \pm 0.1 \mathrm{wt} \%)$ leads to establish that $0.4 \pm 0.1 \mathrm{wt} \%$ of chromium is still in the matrix as a substitutional solid solution. This situation is of importance to understand precipitates formation during nitriding treatment since these chromium atoms will precipitate with nitrogen in order to form semi-coherent platelets. Characteristics of this precipitation will be discussed in the Section 4.

\section{The Nitrided Layer}

This characterization of the nitrided layer has been achieved by the identification of the different kinds of precipitates and by the determination of their size distributions. Both of these experiments will be now discussed below.

\subsection{Precipitate Nature Determination}

After nitriding treatment, the microstructure is completely different from that of the unnitrided material. Tempered martensite laths have almost completely vanished as well as $\mathrm{M}_{23} \mathrm{C}_{6}$ carbides. New precipitates have been generated and three different kinds are observed.

V-rich precipitates are still present in the nitrided layer (see Fig. 6). Their sizes and surface distributions are the same as in the un-nitrided core. SAED confirms their FCC structure (see 


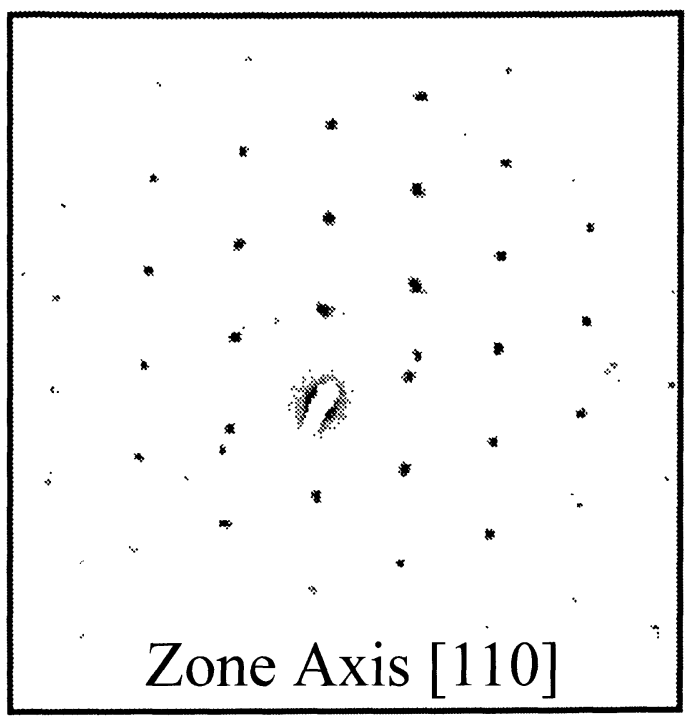

Fig. 7. - SAED pattern for VN precipitates.

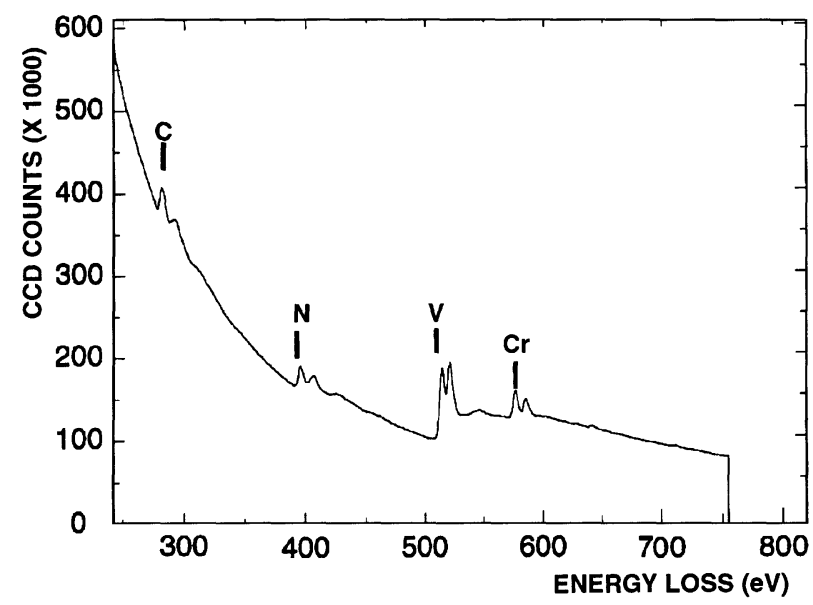

Fig. 8. - EELS spectrum of $\mathrm{M}_{4} \mathrm{C}_{3}$ precipitates.

Fig. 7) and EDS spectra provides a V-rich spectrum containing also carbon and nitrogen peaks. When both elements are present the detector resolution do not allow to separate each element contribution. Thus, Electron Energy Loss Spectroscopy (EELS) experiments are performed and they show unequivocal spectra with well separated carbon and nitrogen peaks leading to conclude that these precipitates are V-rich carbo-nitrides (see Fig. 8). This conclusion is consistent with a previous study [7] where a continuous solid solution between vanadium carbide VC and vanadium nitride VN is found. As nitrogen enters in the un-nitrided material, two different precipitation processes take place leading to two different kinds of precipitates (see Fig. 9).

- From Section 3.2, it has been pointed out that $0.4 \mathrm{wt} \%$ of chromium is still present in 


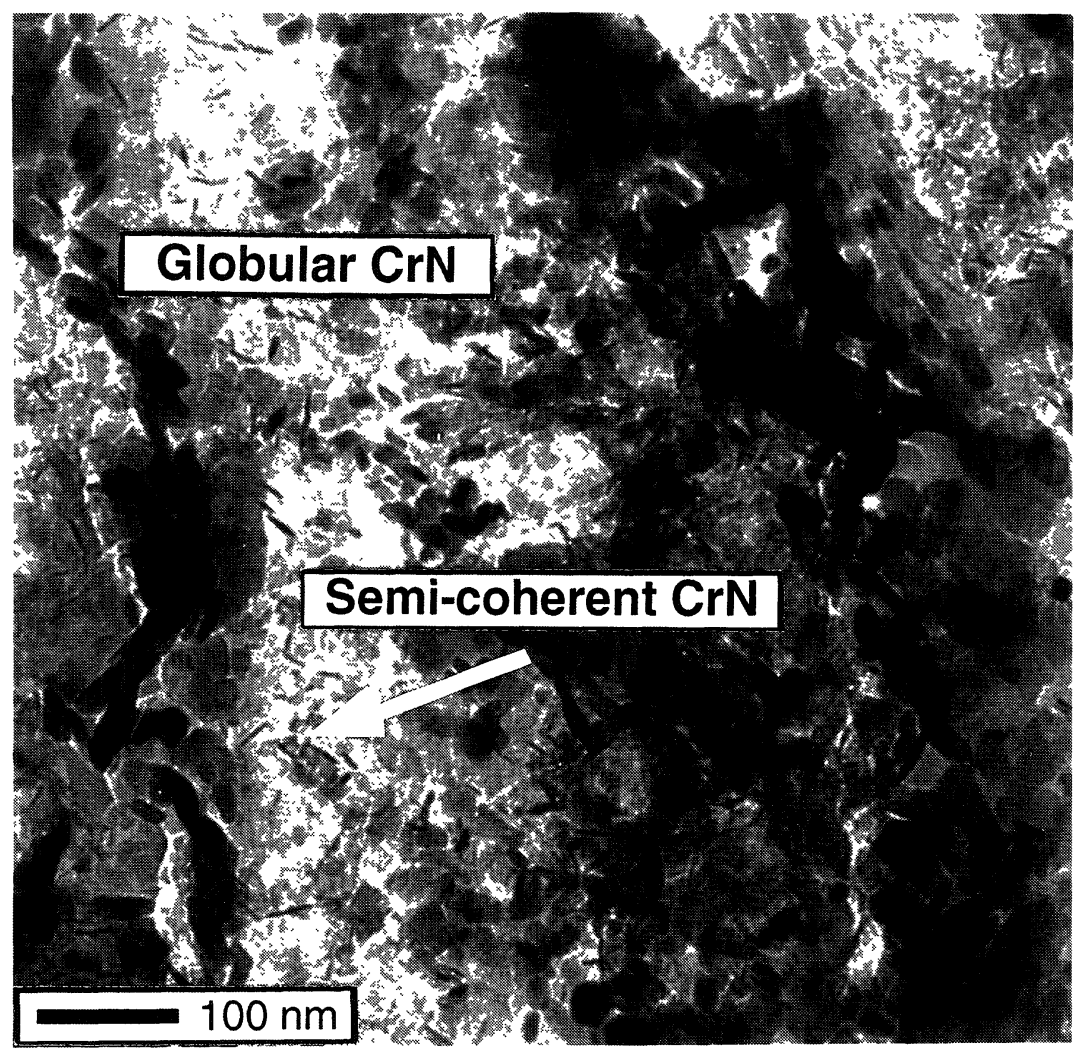

Fig. 9. - TEM micrograph from a carbon film replica of the nitrided layer at depth $=200 \mu \mathrm{m}$.

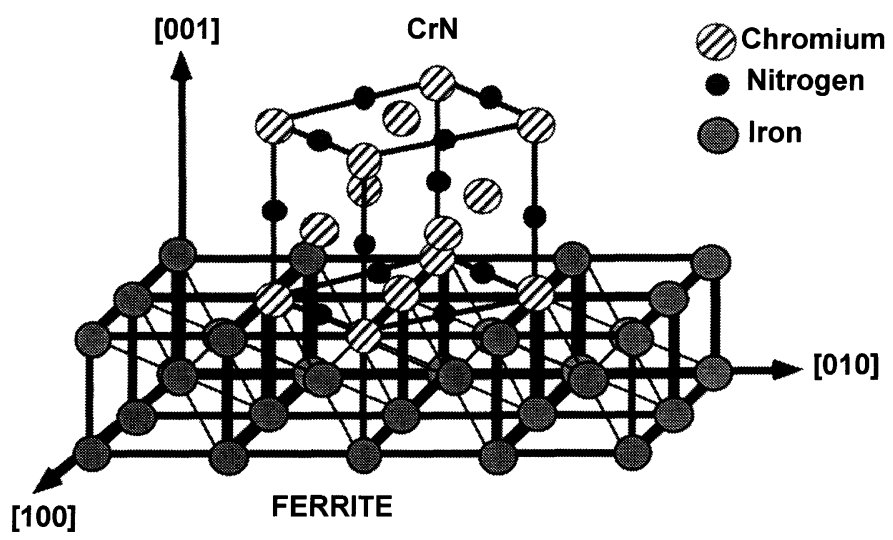

Fig. 10. - Scheme of the Baker-Nutting crystallographic orientation relationship.

the matrix as a solid solution. These chromium atoms will precipitate with nitrogen to form semi-coherent nitrides.

- $\mathrm{M}_{23} \mathrm{C}_{6}$ carbides are gradually dissolved to form also nitrides. 


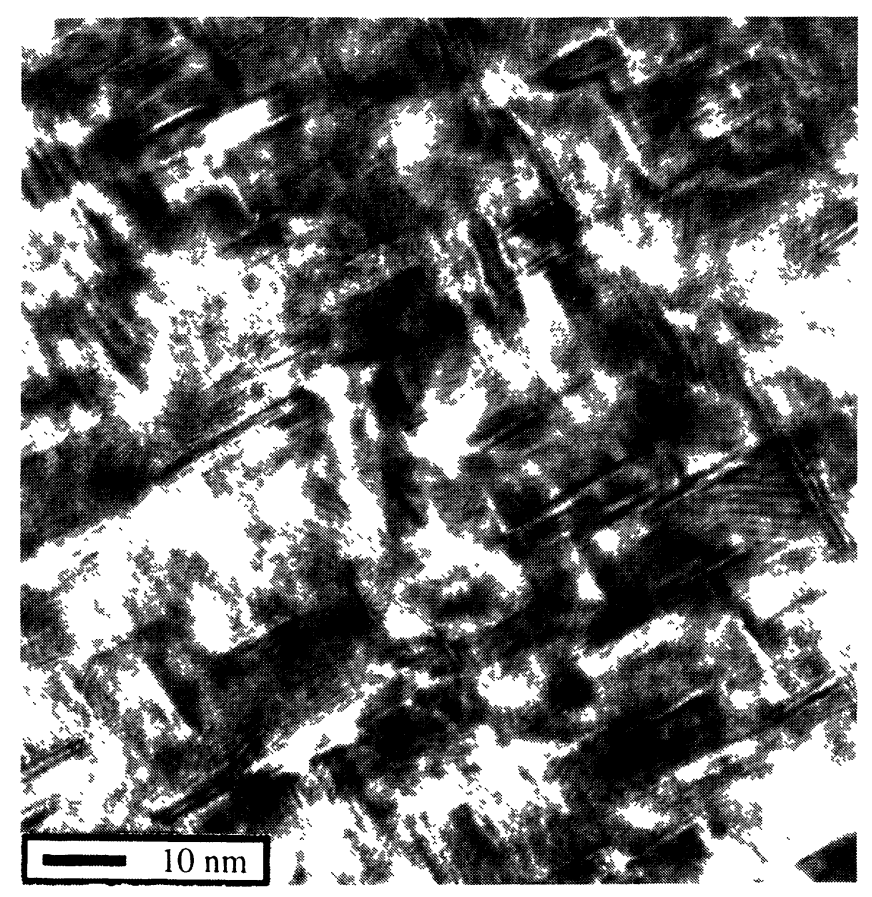

Fig. 11. - TEM micrograph from a thin foil of semi-coherent $\mathrm{CrN}$ precipitates at depth $=200 \mu \mathrm{m}-$ Zone axis [100].

Due to the very strong chemical affinity between chromium and nitrogen, the same structure (i.e. FCC) and chemical composition (i.e. $\mathrm{CrN}$ ) are reported for both kinds of precipitates. Only morphologies and volume fraction values are different due to the way of precipitation.

\subsubsection{Semi-coherent $\mathrm{CrN}$}

The substitutional solid solution of chromium in ferrite leads to the nucleation of $\mathrm{CrN}$ platelets precipitates during nitriding treatment. Literature $[1,3]$ provides data about these precipitates such as their chemical composition or their crystallographic orientation relationship with ferrite. This orientation is called Baker-Nutting orientation [8] and is written as follows:

$$
(001) \alpha / /(001) \mathrm{CrN}:[100] \alpha / /[110] \mathrm{CrN}
$$

A scheme of this relationship is presented in Figure 10. This relation leads to three different spatial orientation for $\mathrm{CrN}$ precipitates on $\{100\}$ plane faces of ferrite structure. TEM micrographs on a thin foil allow the visualisation of these precipitates and their arrangement in the matrix (see Fig. 11). In this figure, the matrix is oriented along a [100] zone axis. Two different populations of precipitates are observed as lines oriented at $90^{\circ}$ from each other. $\{110\}_{\alpha-\mathrm{Fe}}$ planes are also indicated on this figure. They have a misorientation of $\pm 45^{\circ}$ in respect to the $\mathrm{CrN}$ precipitates. Thus, in this configuration, $\mathrm{CrN}$ precipitates are parallel to the $\{100\}_{\alpha-\mathrm{Fe}}$ set of planes. This is exactly the arrangement described by the Baker-Nutting orientation relationship.

In the matching direction (i.e. $[100]$ or $[010]_{\alpha-\mathrm{Fe}}$ ), the misfit $(\delta)$ between ferrite and $\mathrm{CrN}$ lattices is equal to $2.4 \%$. If calculations are made for the normal direction, the misfit equal to $45 \%$. The large difference between both linear misfits makes it obvious that for this system, the 


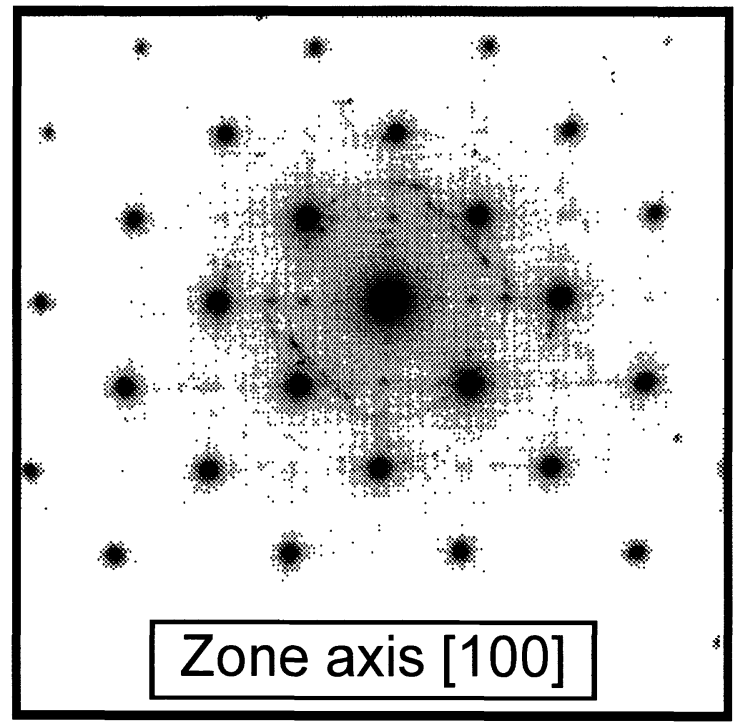

Fig. 12. - SAED pattern for semi-coherent CrN precipitates embedded in the matrix - Zone axis [100].

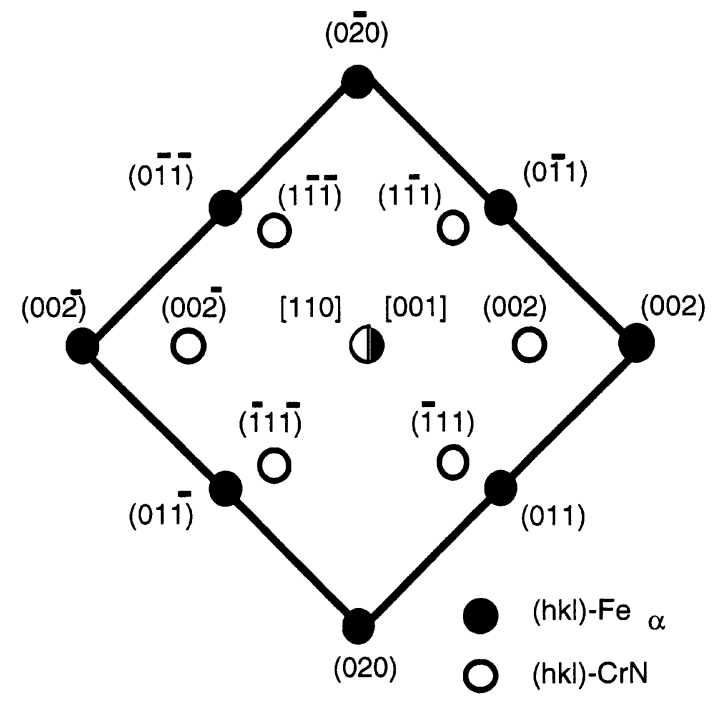

Fig. 13. - Scheme of SAED pattern for semi-coherent $\mathrm{CrN}$ precipitates embedded in the matrix Zone axis $[100]$.

nitrides develop as platelets along $\{100\}_{\alpha-\mathrm{Fe}}$ in conjunction with a tetragonal distortion of the ferrite lattice. Figures 12 and 13 show respectively the experimental SAED pattern obtained from Figure 11 and its corresponding scheme. This type of diffraction pattern have already been studied by $[1,3,9]$ and it provides two elements which confirm the real crystallographic nature of $\mathrm{CrN}$ precipitates and their orientation relationship with respect to the matrix. First, 


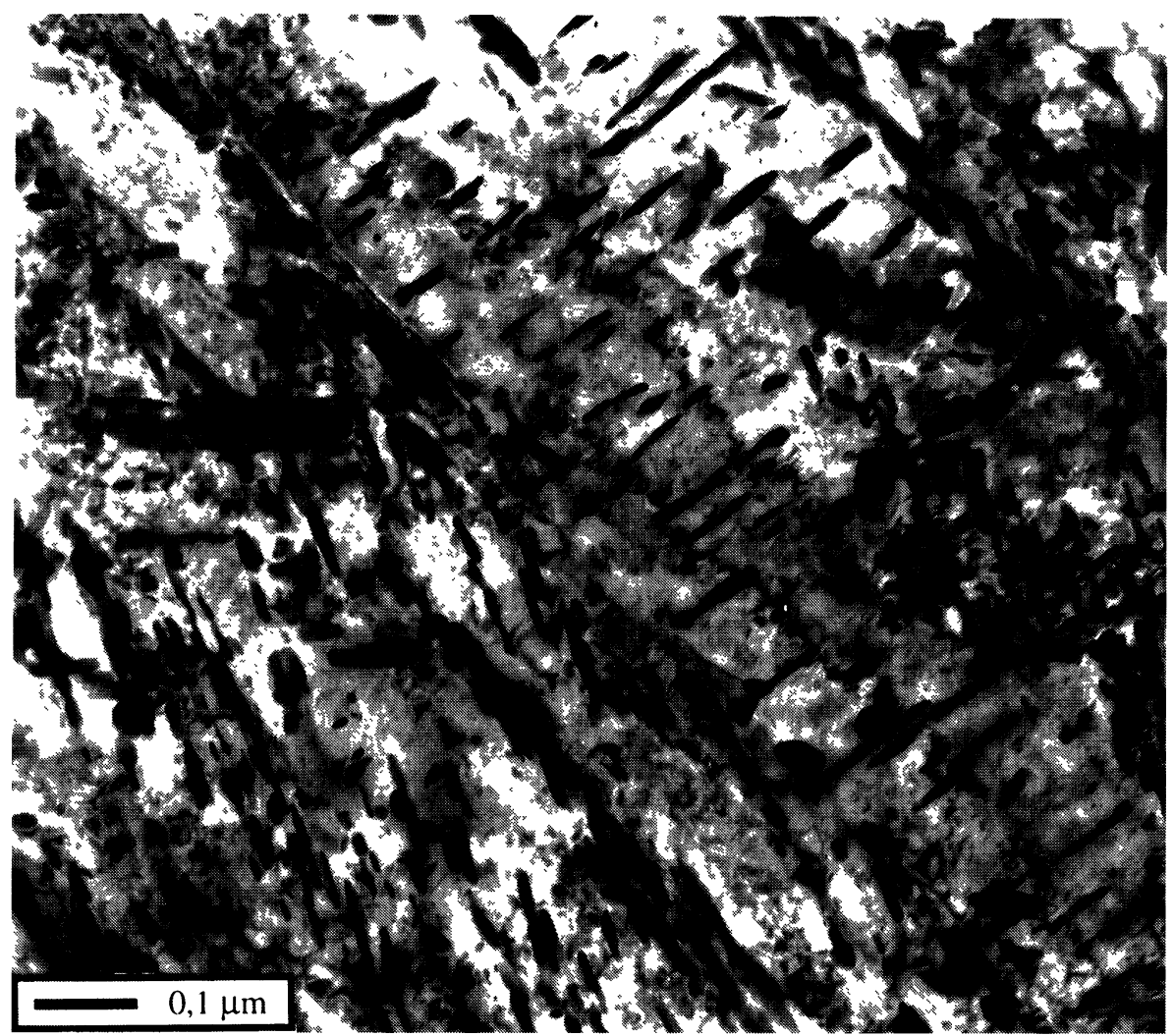

Fig. 14. - TEM micrograph from a thin foil of the un-nitrided material.

the streaking through $\{002\}_{\alpha-F e}$ planes spots is due to the existence of both precipitates families situated at $90^{\circ}$ form each other. Second, the presence of $(002)_{\mathrm{CrN}}$ and some of $\{110\}_{\mathrm{CrN}}$ diffraction spots indicates that these precipitates have already their own crystallographic structure and that they can not be considered as clusters anymore. Despite that no evidence of $\{220\}_{\mathrm{CrN}}$ spots have been found - they may be covered completely by $(020)_{\alpha-\mathrm{Fe}}$ spots - this leads to the confirmation of their FCC structure and their lattice parameter value $\left(a_{\mathrm{CrN}}=\right.$ $0.414 \mathrm{~nm})$.

\subsubsection{Globular $\mathrm{CrN}$}

As it has been pointed out in Section 3.1, $\mathrm{M}_{23} \mathrm{C}_{6}$ precipitates are constituted by chromium, iron and molybdenum atoms. Thus, they are heterogeneous nuclei for precipitation of $\mathrm{CrN}$ nitrides. Figures 14 and 15 make a comparison between the un-nitrided core and the nitrided layer microstructure. Intralath nitrides are found in the nitrided layer with the same layout as that of the un-nitrided core. A higher magnification (Fig. 16) allows the visualization of their distribution in the matrix. In this figure, these precipitates correspond to globular black particles. Their structure identification and chemical compositions are obtained from SAED patterns and EDS spectra (see Fig. 17). Both techniques confirm respectively their FCC structure $(a=0.414 \mathrm{~nm})$ and their Cr-rich composition with the presence of molybdenum. EELS experiments (Fig. 18) confirm the presence of chromium and nitrogen but no carbon is detected. These observations lead to the conclusion that these precipitates are chromium 


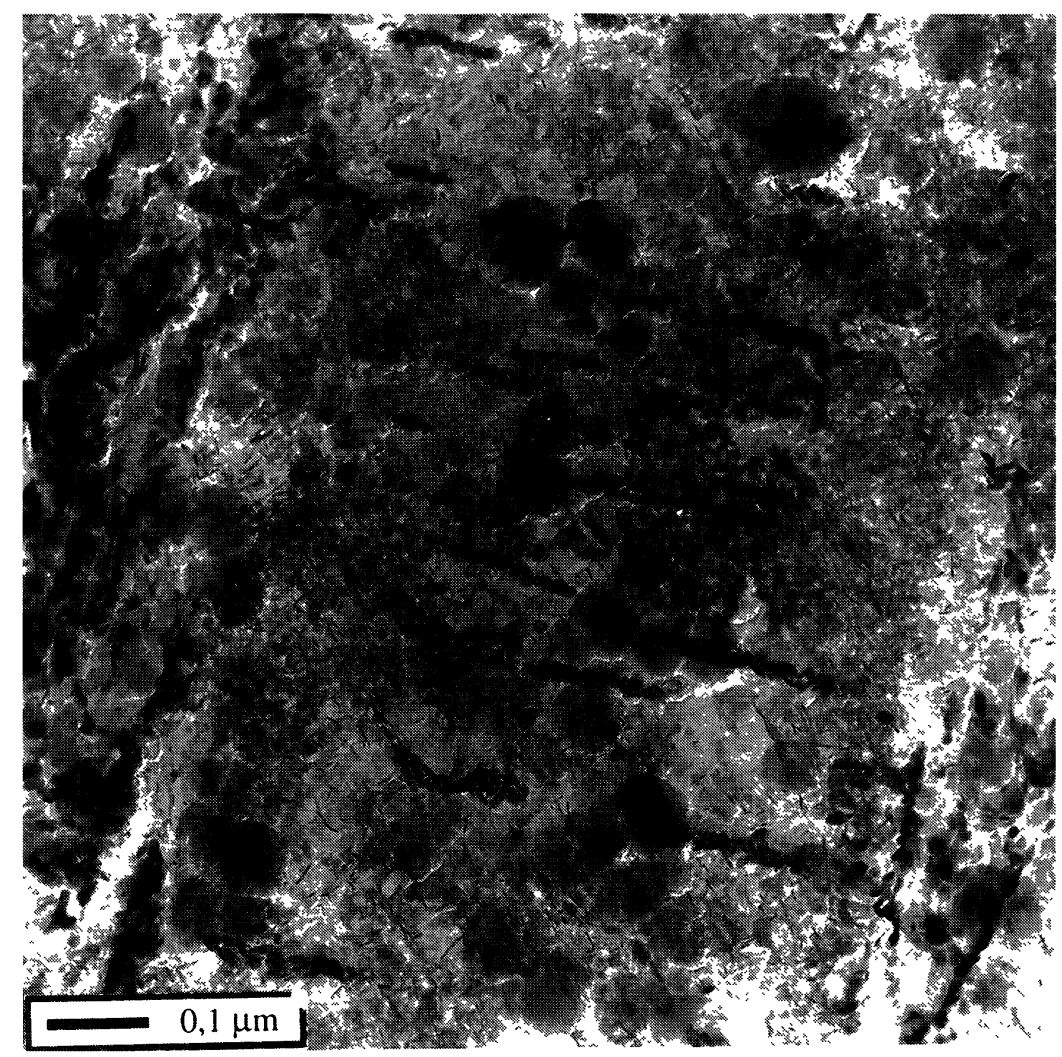

Fig. 15. - TEM micrograph from a carbon film replica of the nitrided layer at depth $=200 \mu \mathrm{m}$.

nitrides $\mathrm{CrN}$ with a partial substitution by molybdenum atoms. The comparison between their orientation relationship with respect to the ferritic matrix and those of semi-coherent precipitates leads to assume that both of them have the same orientation relationship with the matrix (i.e. Baker-Nutting).

\subsection{Precipitate Size Characterization}

For both families of $\mathrm{CrN}$ precipitates (globular and semi-coherent), the size distributions have been studied as a function of depth by carbon film replicas. These replicas were taken on a cross-section of the nitrided layer. Depths are determined by measuring the distance from the surface limit directly on the replica. Thus, all depths are available on one replica.

For globular $\mathrm{CrN}$ precipitates, three different depths were investigated and about a hundred of particles sizes were measured each time. As it has been pointed out in Section 4.1.2, these precipitates show an ellipsoid shape. Thus, size characterization is made on their length (see Fig. 19) and their width (see Fig. 20). Results show that precipitate size distributions do not change with depth. Their length is ranging between 5 and $40 \mathrm{~nm}$ with a mean value of $20 \mathrm{~nm}$ and their width is ranging between 2 and $20 \mathrm{~nm}$ with a mean value of $5 \mathrm{~nm}$.

For semi-coherent $\mathrm{CrN}$, same experimental conditions were used. These precipitates are always seen by cross section. Their maximum diameter as well as their thickness have been measured for two depths $(z=00 \mu \mathrm{m}$ and $z=400 \mu \mathrm{m})$. The thickness distribution is found 


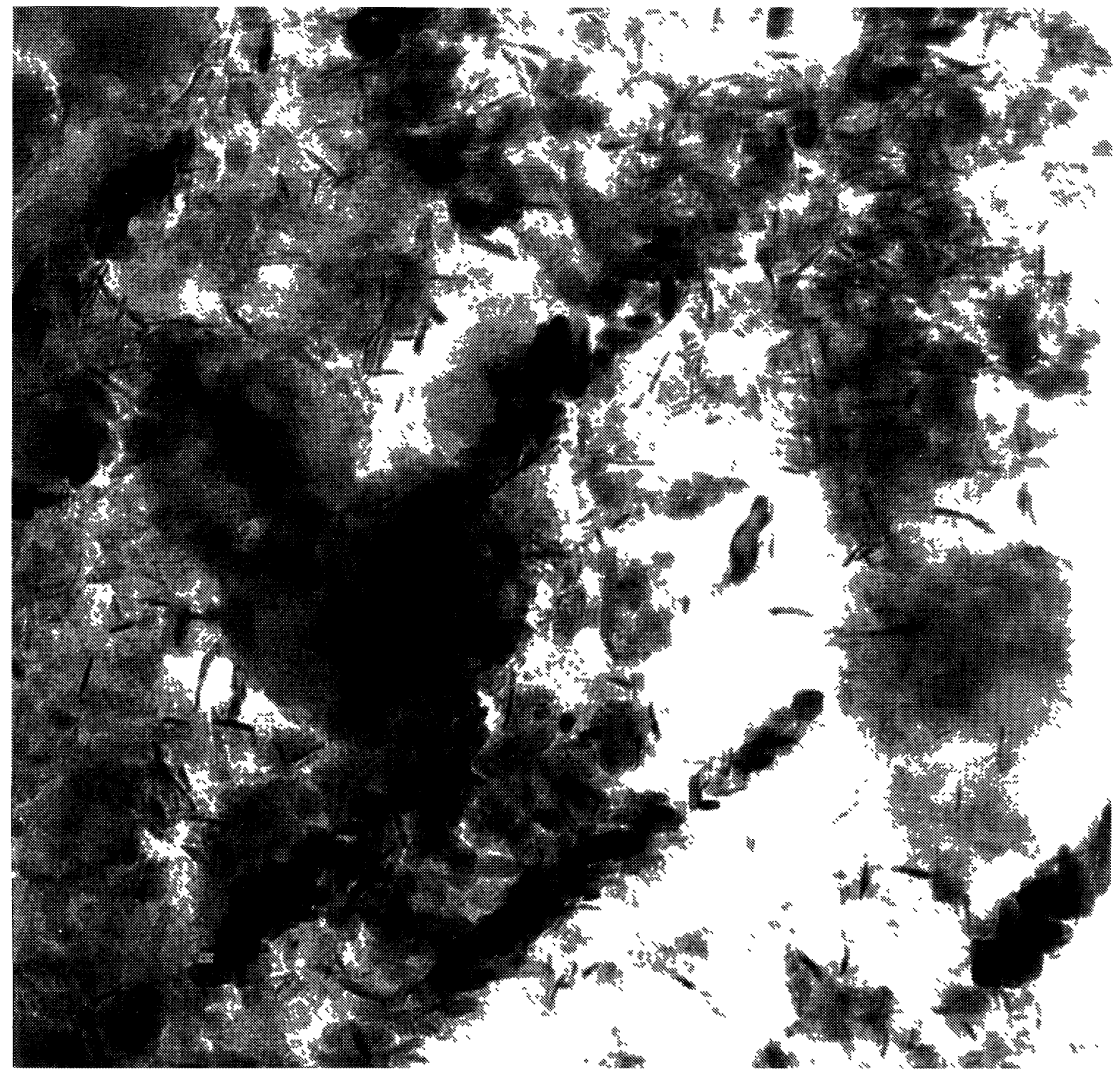

Fig. 16. - TEM micrograph from a carbon film replica of the nitrided layer at depth $=200 \mu \mathrm{m}$.

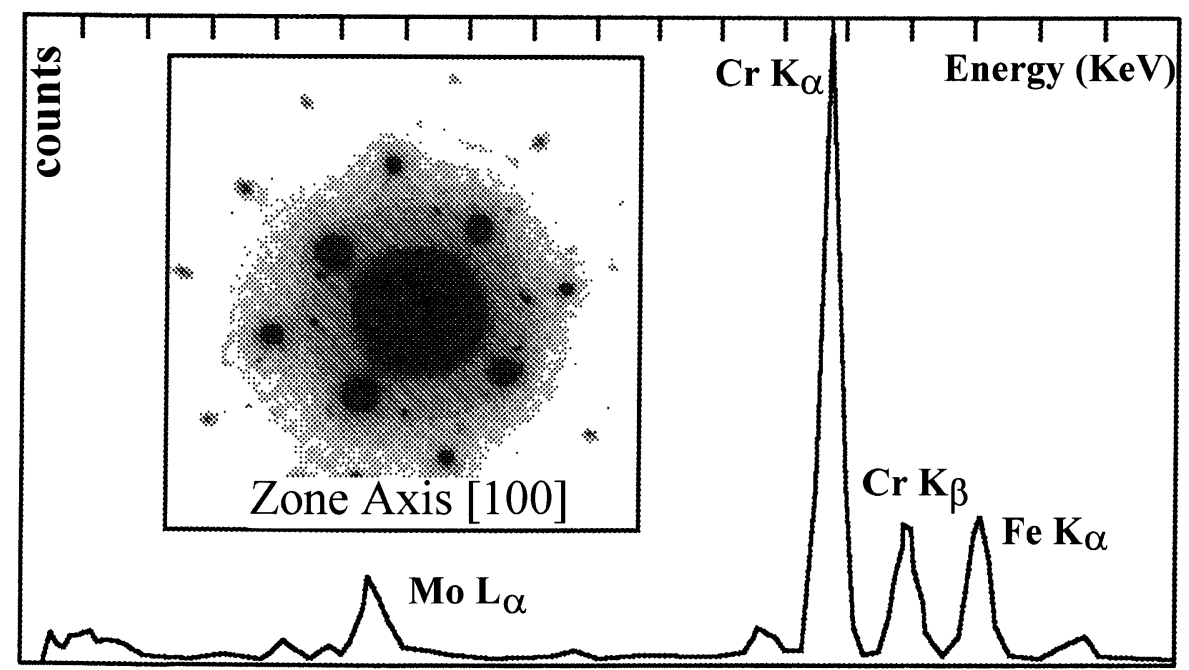

Fig. 17. - EDS spectrum and SAED pattern for globular CrN precipitates. 


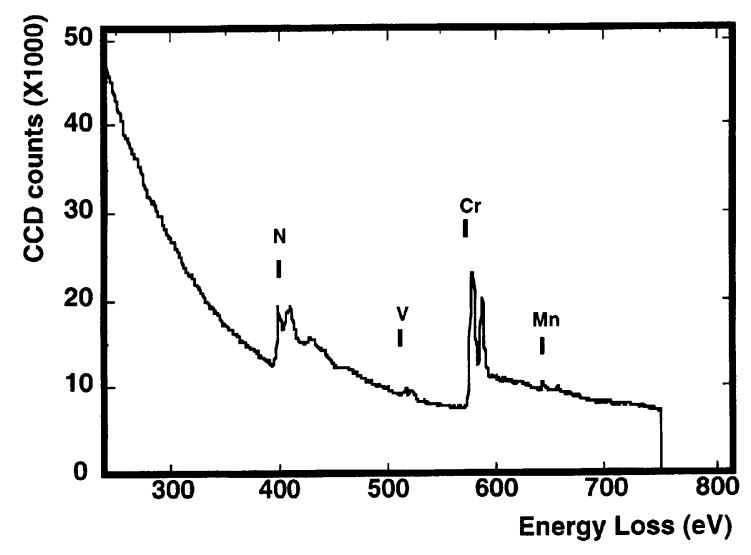

Fig. 18. - EELS spectrum of $\mathrm{CrN}$ precipitates.

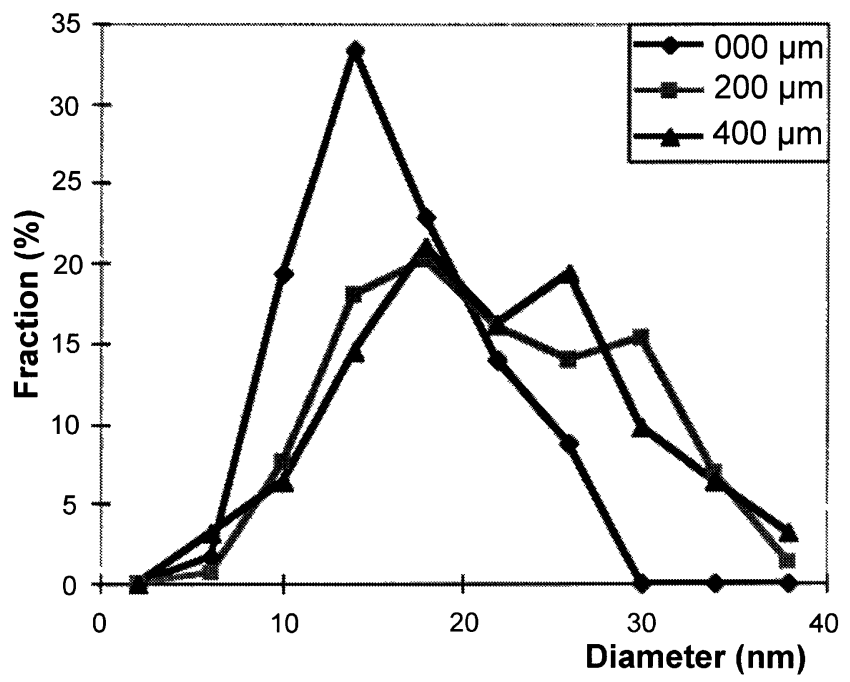

Fig. 19. - Globular $\mathrm{CrN}$ precipitates lengths distribution as a function of depth for a nitriding treatment time of $120 \mathrm{~h}$.

almost constant with depth at $2 \mathrm{~nm}$. As the lattice parameter for $\mathrm{CrN}$ is $0.414 \mathrm{~nm}$, a precipitate thickness of $2 \mathrm{~nm}$ represents only 4 crystallographic cells stacked up. Histogram for diameter distribution is presented in Figure 21. Diameters are ranging between 1 to $20 \mathrm{~nm}$ with a mean value of $15 \mathrm{~nm}$ and here again, size distributions do not show any difference in respect with depth.

\section{Discussion}

Local chemical conditions induced in the matrix by the nitriding treatment allow the dissolution of former carbides and the formation of globular CrN nitrides. Experiments confirm a BakerNutting orientation relationship for these precipitates. This observation leads to the conclusion 


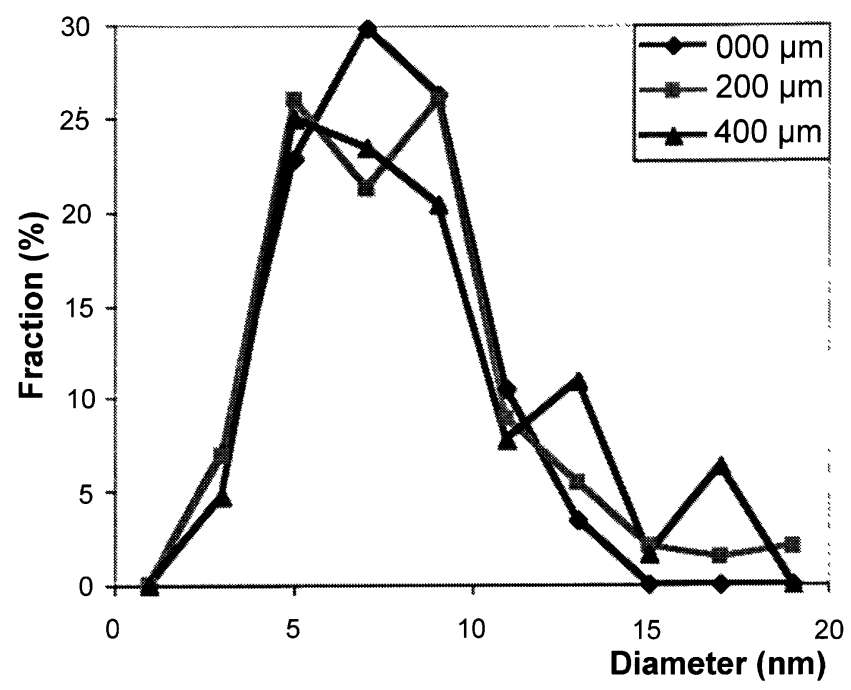

Fig. 20. - Globular $\mathrm{CrN}$ precipitates widths distribution as a function of depth for a nitriding treatment time of $120 \mathrm{~h}$.

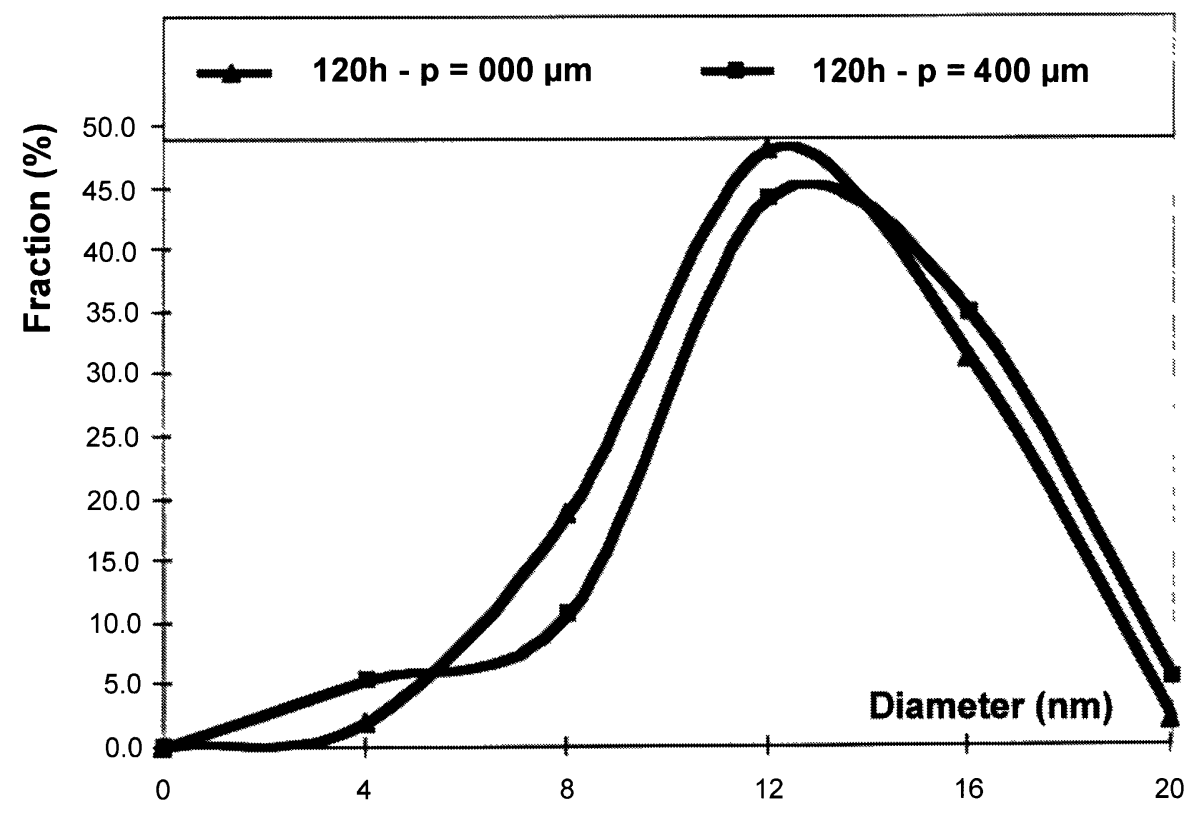

Fig. 21. - Semi-coherent precipitates diameters distribution as a function of depth for a nitriding treatment time of $120 \mathrm{~h}$.

that tempering carbides (of the un-nitrided material) must be dissolved before the nitride precipitation takes place in the matrix. From literature [6], the solubility limit of Fe in $\mathrm{CrN}$ is found to be very low. Indeed, no evidence for iron was found on EDS spectra from extracted precipitates. Thus, diffusional processes must take place during treatment in order to create 
a demixtion between chromium and molybdenum atoms on one hand and iron atoms on the other hand. Since alloying elements are already concentrated in small regions (carbides), the demixtion should occur in a short time. Iron does not need to diffuse over a long distance. In the same time, the precipitation of $\mathrm{CrN}$ nitrides occurs in the matrix. From a kinetic point of view, the $\mathrm{CrN}$ nitride precipitation rate is limited by the tempering carbide dissolution rate. The first step is the formation of $\mathrm{CrN}$ semi-coherent precipitates with the Baker-Nutting orientation relationship which transform quickly in incoherent globular precipitates since alloying element concentration is very high in these zones.

The size characterization of these precipitates shows that precipitate size distributions do not change with depth. This behaviour was not expected since nitriding is a diffusion controlled process and the growth of precipitates with depth should be observed. For chromium alloyed steels, the depth in nitrided layers can be converted in time via the Wagner law [10] considering that the layer thickness is proportional to the square root of nitriding time. Quantitative WDS measurements have detected nitrogen until $680 \mu \mathrm{m}$ in depth. Replicas observations at $600 \mu \mathrm{m}$ in depth have shown that almost $50 \%$ of the whole volume fraction of semi-coherent CrN have already precipitated. At this depth, the previous formula allows the calculation of the nitrogen presence time in the bulk and gives 35 hours. Thus, the nucleation of this kind of precipitates takes less than 35 hours to occur.

On the other hand, first globular CrN precipitates have been seen in the range 500-600 $\mu \mathrm{m}$. Their precipitation takes a little bit more time to occur since $\mathrm{M}_{23} \mathrm{C}_{6}$ carbides demixtion must appear before their precipitation.

When the nucleation is complete, no more solute atoms are available for nitrogen precipitation but the nitrogen gradient is still present between the surface and the un-nitrided core. This gradient leads to a high local nitrogen content which does not contribute to the precipitate coalescence. Thus, precipitates remain with their size determined by the local solute atoms amounts leading to a constant size distribution as a function of depth.

\section{Conclusion}

Industrial nitriding of an aeronautic steel has been performed and nitrided layer as well as un-nitrided core have been investigated in order to characterize the precipitates nature and their size distributions.

The quenched-tempered microstructure of $32 \mathrm{Cr} 13 \mathrm{MoV}$ steel is constituted by intralaths and interlaths $\mathrm{M}_{23} \mathrm{C}_{6}$ carbides with a volume fraction of $6 \% . \mathrm{M}_{4} \mathrm{C}_{3}$ carbides are also detected with a volume fraction of $0.7 \%$. They are respectively chromium and vanadium rich precipitates with in both cases iron and molybdenum atoms in substitution. All these carbides do not precipitate all chromium atoms available in the matrix and $0.4 \mathrm{wt} \%$ are still present in ferrite as a solid solution.

Thus, during nitriding treatment, nitrogen precipitates these atoms to form semi-coherent $\mathrm{CrN}$ nitrides. They have a Baker-Nutting crystallographic orientation relationship with ferrite. In the same time, $\mathrm{M}_{23} \mathrm{C}_{6}$ carbides are dissolved and induce the precipitation of incoherent globular $\mathrm{CrN}$ with a layout in the matrix induced by a first stage of precipitation in coherence with respect to the matrix. The size evolution for both types of precipitates as a function of depth shows that precipitates sizes are independent of depth. This observation indicates that these precipitates have a fast nucleation kinetic and a slow growth one. These experiments lead to the understanding of the formation of nitrides during nitrading treatment. 


\section{References}

[1] Phillips V.A. and Seybolt A.U., Trans. Metallurg. Soc. AIME 242 (1968) 2415-2422.

[2] Hekker P.M., Rozendaal H.C.F. and Mittemeijer E.J., Excess Nitrogen And Discontinuous Precipitation In Nitrided Iron-Chromium Alloys, in Nitrogen in metals and alloys, 114, New York, Vol. 20 (1985) pp. 718-729.

[3] Mortimer B., Grieveson P. and Jack K.H., Scandin. J. Metal. 1 (1972) 203-209.

[4] Sundman B., Jansson B. and Anderson J.O., The Thermo-Calc Databank System, in Calphad, Grenoble, Vol. 9 (1985) pp. 153-190.

[5] Barrallier L., Génèse des contraintes résiduelles de nitruration, Ph.D. thesis (ENSAM, 1992).

[6] Goldschmidt H.J., Interstitial Alloys (Butterwoth and Co Ltd, 1967).

[7] Duwez P. and Odell J., J. Electrochem. Soc. 97 (1950) 299.

[8] Baker R.G. and Nutting J., Precipitation Process in Steels, I.S.I. Special report 64 (1959).

[9] Somers M.A.J., Lankreijer R.M. and Mittemeijer E.J., Philos. Mag. A 59 (1989) 353-378.

[10] Lightfoot B.J. and Jack D.H., Kinetics of Nitriding With and Without White-Layer Formation, in Heat treatment (1973) pp. 59-65. 